\title{
Which children in England see the health visiting team and how often?
}

\author{
Commentary by Jenny Woodman, ${ }^{1}$ Katie Harron ${ }^{2}$ and Dave Hancock
}

In June 2021 Public Health England (PHE) published its first set of statistics describing additional health visiting contacts (PHE, 2021a). Jenny Woodman, Katie Harron and Dave Hancock comment on what these statistics and other research (including their own) tells us about patterns of health visiting contacts at a national level.

\section{What's different about these new statistics from PHE?}

Since 2016, PHE has published statistics on the percentage of children who have received their mandated health reviews in the last year: the new birth visit, 6-8 weeks, 12 months and $2-21 / 2$ years (PHE, 2021b). PHE provides the number but not percentage of children receiving their mandated antenatal contact with the health visiting team. This information on mandated health checks is published for all of England and separately for each local authority and is based on an 'interim reporting' system where local authorities submit information to PHE. An easy way of accessing these statistics is through the PHE Fingertips tool (PHE, 2021c).

The statistics published by PHE in June are a first step in getting a more complete picture of health visiting activity across England, based on data from children aged under 5 years in 2019-2020. The new statistics describe 'additional' contacts between families and the health visiting team, over and above the five mandated health reviews. They are based on a different data source to the PHE statistics about the mandated health reviews: the Community Services Dataset (CSDS). CSDS contains information about community services in England since 2015 and is operated by NHS Digital. CSDS comes with a warning: it is classed by NHS Digital as 'experimental data' - to be used and interpreted with caution because of known problems with the quality of data.

\section{Why are the national statistics and national data important}

Bringing together and analysing information about health visiting services from all areas in England is one key part of understanding what is being delivered to which families in which types of contexts. Being able to describe health visiting activity on a national level, including how health visiting varies across the country, is a first step for research looking at the impact of health visiting. Having a national picture, including differences between areas, is an important part of making the case for the importance of health visiting and can be part of discussions about funding at a national level.

\section{What can't the national data tell us}

The national statistics are of course only one part of the picture and come with substantial caveats which we describe below. Also, they can't tell us about the 'art' of health visiting. They can't tell us about the nuances of making assessments and building relationships with families or about the quality or meaning of a 'contact', which will vary enormously. National information about contacts will always need to be interpreted with a deep understanding of how health visiting works for individual families and knowledge of differences between local authorities for example in the types of families with preschool children in an area or wider services available for a family. 


\section{What do we know about the mandated health reviews at a national level?}

\section{Before the covid-19 pandemic}

We know that not all children were receiving their mandated health reviews from the health visiting teams before the covid-19 pandemic. Across England, the vast majority of new birth visits were completed in 2019-20 (98\%). But this fell to $85 \%$ for the $6-8$ week review, $85 \%$ for the 12 month review and 79\% for the 2-21/2 year review (PHE 2021a, Fraser et al 2020, OCC 2020). That means 1 in 5 children did not receive their 2-21/2 year review. According to a survey by the Institute of Health Visiting, most new birth visits were carried out by a qualified health visitor, compared to only $10 \%$ of $2-2 \frac{1}{2}$ year reviews (iHV, 2020). The welldescribed backdrop to these statistics is increasing need for support among children and families and a health visiting service dealing with shrinking budgets and falling health visitor numbers (OCC 2020).

There is some uncertainty about whether some children in England were systematically more likely to get their mandated health reviews than others before 2020 and the covid-19 pandemic. The Leadsom review concluded that there was 'emerging evidence' from PHE (2021d) that babies from deprived areas and from minority ethnics groups were less likely to get their mandated health reviews than other babies (Best Start for Life, 2021). Other research using CSDS found that children in the most deprived areas were slightly more likely to miss out on a 2-21/2 year review but no patterns for ethnicity or having a 'safeguarding vulnerability' recorded. (Fraser, 2020),. The same research reported that only $44 \%$ of children who had a 'Looked After Child' code in their CSDS record also had evidence of a 2$2 \frac{1}{2}$ year review (Fraser, 2020).

One of the reasons for the uncertainty about which children are getting their mandated health reviews is the quality of CSDS. Only about a quarter of local authorities in England have nearly-complete data in CSDS, although many of these local authorities will likely have their accurate and complete records in their own systems. There are different ways of dealing with the missing information in CSDS, which can lead to discrepancies between findings (e.g. around ethnicity) or uncertainty about whether the findings apply to the whole of England. For example, the finding that Looked After Children were very much less likely to have a $2-21 / 2$ year mandated review in $2018 / 9$ can only be treated as a hypothesis for further investigation as it was based on data from 13 local authorities in CSDS who had sufficiently complete information in CSDS for both Looked After Child status and the 2-21/2 year mandated review (Fraser, 2020).

In summary, we know that not all children were receiving their mandated health reviews before 2020 but due to problems with CSDS we are very unsure about whether children are missing out on these health reviews at random or whether there is a pattern, with meaning that certain types of families were more likely to miss out than others.

\section{What do we know about additional contacts from the health visiting team at a national level?}

The new statistics from PHE in June 2021 suggest that children in the most deprived neighbourhoods are more likely to get additional contacts, which is consistent with the 
research on the 2-21/2 year mandated review (PHE, 2021a; Fraser, 2020). This is in contrast to the emerging (but uncertain) patterns of mandated health reviews. When the study on the $2-2 \frac{1}{2}$ year mandated review took into account additional face-to-face contacts (not letters, not administrative phone calls), the patterns of the 2-21/2 year check were reversed for deprivation and disappeared for Looked After children (Fraser, 2020). Children aged 2 who were identified as 'Looked After' in this study saw a member of the health visiting team an average of 5 times in 12 months, compared to an average of 3 times for children with a 'vulnerability factor' recorded, an average of twice for children living in the most deprived neighbourhoods and an average of once for all children (Fraser, 2020). The new PHE analyses and other research raises questions about why some groups of children (deprived and Looked After) seem to be seeing the health visiting team but perhaps not getting their mandated health reviews. Although there are still question marks about the patterns of additional contacts across England before the 2020 covid-19 pandemic (because of the problems with CSDS), findings are more consistent across PHE statistics and research than for the mandated reviews.

\section{Since the covid-19 pandemic}

We don't yet have a national picture of health visiting contacts from 2020 onwards (the first lockdown to mitigate the spread of covid-19 in England was in March 2020). PHE have not yet published statistics for 2020 onwards. Research studies suggest that did contacts switch from face-to-face to digital during the first lockdown in March-June 2020 but contacts also dropped in frequency. A survey of parents between April and June 2020 found that only $11 \%$ of 3,903 parents with children under two had seen a visitor face to face during the first lockdown that started in late March 2020 (Babies in lockdown, 2020). Another survey of 861 professionals in May 2020 found that a third of respondents believed that at least half of the vulnerable families on their caseload did not receive the level of contact needed during the pandemic to keep their children safe, with health visitors most often saying this (Barlow et al, 2020).

\section{Conclusions}

Despite on-going uncertainty about how health visiting contacts are patterned across England, the new PHE analyses are a step in the right direction. Despite the problems with CSDS it remains an extremely important data source and as data quality of CSDS improves, the data available for research will be larger, more generalisable for England and will support more robust conclusions. In the meantime, hypotheses emerging from CSDS are a good place to start building an evidence-base about health visiting across England, with more work needed to test emerging findings and contextualise them in the nuances and meaning of health visiting practice in different areas across England.

However, in order to produce reliable findings, researchers and policy makers require high quality national data from health visiting services linked to other information from other health services, social care and education for the whole of England. NHS Digital and PHE are undertaking quality improvement work to address the missing data in CSDS. National policies and/or funding to accelerate the pace of CSDS quality improvements might be one way that data quality can be improved so that it is clear how many and which types of contacts from health visiting services are happening in England and how this is different for certain groups of children or for specific local areas. Without this data, it is difficult to work 
out how health visiting is impacting on child outcomes at a national level and how that varies across different local authorities in England

\section{AFFILIATIONS}

1: Dr Jenny Woodman, Associate Professor of Child and Family Policy, UCL Social Research

Institute, London, WC1H 00A j.woodman@ucl.ac.uk

2: Dr Katie Harron, Associate Professor of Statistics, Population, Policy \& Practice Dept, UCL

Great Ormond Street Institute of Child Health. London. WC1N 1EH, UK k.harron@ucl.ac.uk

\section{References}

PHE (2021a) Contacts other than those mandated and referrals by health visitors.

https://www.gov.uk/government/publications/contacts-other-than-those-mandated-andreferrals-by-health-visitors (accessed 21 June 2021)

PHE (2021b) Child and maternal health statistics

https://www.gov.uk/government/collections/child-and-maternal-health-statistics\#healthvisitor-service-delivery-metric (accessed 23rd June 2021)

PHE (2021c) Child and Maternal Health. https://fingertips.phe.org.uk/profile/child-healthprofiles (accessed 21 June 2021)

Office for the Children's Commissioner (OCC). 2020. Best Beginnings in the Early Years: A proposal for a new early years guarantee to give all children in England the best start in life.

https://www.childrenscommissioner.gov.uk/wp-content/uploads/2020/07/cco-best-beginnings-inthe-early-years.pdf (accessed 23 June 2021)

Fraser C, Harron K, Barlow J, Bennett S, Woods G, Shand J, et al. 2020. How can we use the community services dataset (CSDS) for research into health visiting? Available at

https://www.ucl.ac.uk/children-policy-research/sites/children-policy-

research/files/using csds for research report 08.10.20.pdf [last accessed 14.01.21].

Best Start for Life, 2021: H M Government. The Best Start for Life: a vision for the 1,001 Critical Days.

2021. The Early Years Healthy Development Review Report.

https://assets.publishing.service.gov.uk/government/uploads/system/uploads/attachment data/file 1973112/The best start for life a vision for the 1001 critical days.pdf [accessed 23rd June 2021)

Babies in Lockdown: listening to parents to build back better (2020). Best Beginnings, HomeStart UK, and the Parent-Infant Foundation

https://babiesinlockdown.files.wordpress.com/2020/08/babies-in-lockdown-main-report-

final-version-1.pdf (accessed 23rd June 2021)

Barlow et al, 2020 https://www.ucl.ac.uk/children-policy-research/sites/children-policyresearch/files/the impact of the covid-

19 pandemic on services from pregnancy through age 5 years final report 101120.pd f (acessed 23rd June 2021)

Public Heath England (2021d). Characteristics of children receiving Universal Health Visitor Reviews: Experimental analysis of the Community Services Dataset. Available at https://www.gov.uk/government/publications/characteristics-of-children-receivinguniversal-health-visitor-reviews (accessed 24th June 2021). 
